\title{
SINERGIA
}

REVISTA DO INSTITUTO DE CIÊNCIAS ECONÔMICAS, ADMINISTRATIVAS E CONTÁBEIS (ICEAC)

\section{ATUACÃO DE INFLUENCIADORES DIGITAIS: RELAÇÃO ENTRE CREDIBILIDADE E INTENÇÃO DE COMPRA DOS NOVOS CONSUMIDORES}

\author{
CAROLINE SOARES GONCALVES \\ LARISSA MARTINATTO DA COSTA \\ CLÁUDIA RODRIGUES MAIA
}

\begin{abstract}
RESUMO
As marcas buscam influenciadores para agregar valor, visto que, nesse mundo de marketing pós-moderno, necessitam ganhar confiança de seus consumidores e clientes, através de "rostos" conhecidos que passam a sensação de familiaridade. Este artigo teve como objetivo verificar a credibilidade da atuação de influenciadores digitais nas mídias sociais sobre intenção de compra dos consumidores e se essa influência é alterada quando o produto é de baixo envolvimento ou alto envolvimento. O estudo caracteriza-se como um experimento realizado com 120 participantes. Os resultados indicaram que a associação da marca à celebridade não teve boa aceitação por parte dos consumidores respondentes que avaliaram melhor a possibilidade de compra dos produtos com modelos desconhecidos. Além disso, foi verificado que o tipo de produto (alto/baixo envolvimento) apresentado por influenciadores digitais não interfere na intenção de compra do consumidor.
\end{abstract}

Palavras chave: influenciadores, credibilidade, intenção de compra, produto baixo envolvimento, produto alto envolvimento.

\begin{abstract}
Brands are looking for influencers to add value, since in this world of postmodern marketing they need to gain trust from their consumers and customers through familiar "faces" that convey a sense of familiarity. This article aimed to verify the credibility of the influence of digital influencers in social media on consumers' purchase intentions and whether this influence is altered when the product is of low or high involvement. The study is characterized as an experiment performed with 120 participants. The results indicated that the brand association did not get a good acceptance from the respondent consumers who better evaluated the possibility of buying the products with the unknown models. In addition, it was found that the product type (high / low involvement) is not interfered with in the consumer's purchase intention.
\end{abstract}

Keywords: influencers, credibility, purchase intention, product low involvement, product high involvement.

Recebido em: 16-08-2018 Aceito em: 23-05-2019

\section{INTRODUÇÃO}

As marcas buscam influenciadores para agregar valor, visto que, nesse mundo de marketing pós-moderno, necessitam ganhar confiança de seus consumidores e clientes, através de "rostos" conhecidos que passam a sensação de familiaridade. Com isso, é natural a busca por um influenciador que já conquistou a confiança e admiração do seu público e isso se torna uma estratégia de êxito de acordo com a visão das marcas. Em comparação com a estratégia de promoção de celebridades, o uso de influenciadores de mídia social é considerado mais confiável devido à sua capacidade de construir relacionamento com os consumidores (BERGER et al., 2016), especialmente para empresas voltadas para as gerações mais jovens.

Há uma busca pelo influenciador mais alinhado com os valores da marca, justamente para passar a sensação de verdade na sua fala. Em vista da gama de tipos existentes no mercado, como, por exemplo: celebridades, autoridades, especialistas, jornalistas e youtubers, essa escolha pode ser um fator determinante do sucesso na propaganda. Além disso, os influenciadores de mídia social também podem mostrar resultados atraentes na cobertura da mídia e na persuasão do consumidor (BOOTH; MATIC, 2011). Pode-se dizer que, no momento, há uma profissionalização nesse mercado.

\footnotetext{
Bacharel em Direito e Administração e Mestranda em Administração pela Universidade Federal do Rio Grande. E-mail: karol_zitah88@hotmail.com

"Mestra em Administração pela Universidade Federal do Rio Grande. MBA Executivo em Gestão Pública pelo Centro Universitário Barão de Mauá. Graduada em Marketing pela Universidade Paulista.

Doutoranda em Administração pela Universidade Federal do Rio Grande do Sul. Mestra em Administração pelo PPGA FURG. Graduada em Administração pela Universidade Federal do Rio Grande.
} 
Influenciadores estão presentes em todos os setores: saúde e fitness, moda e beleza, alimentos, alta tecnologia e outros (RAGGATT et al., 2018; KLASSEN et al., 2018). Os blogueiros do YouTube, Instagram e Facebook frequentemente apresentam os produtos que testaram, fornecendo sua opinião ou promovendo-os online para outros usuários. As postagens de influenciadores no Instagram geralmente tomam a forma de uma imagem ou vídeo enriquecido com conteúdo incorporado e uma descrição textual. A popularidade dos blogueiros trouxe uma nova forma de marketing chamada "marketing de influência", em que as marcas colaboram com os influenciadores para promover seus produtos (DE VEIRMAN et al., 2017).

Aproveitando a infinidade de plataformas de mídia social como Facebook, Instagram, Twitter e Youtube, os influenciadores de mídia social são usados para divulgar informações sobre produtos e promoções mais recentes para seguidores online (MARKETHUB, 2016). Marcas famosas e grandes empresas dos mais variados segmentos já utilizam essa estratégia como canal para converter a propaganda em vendas, já que a aprovação dos influenciadores digitais em relação a um produto pode transformar os padrões de consumo dos seus seguidores, principalmente os jovens. Os influenciadores de mídias sociais normalmente se envolvem com seus seguidores, atualizando-os regularmente com as informações mais recentes (LIU et al., 2012).

Ao investir em marketing de influência, o diferencial é buscar o público-alvo correto da marca e depois verificar quem os influencia. Diversas empresas contratam para estrelar seus comerciais os influenciadores ao invés de celebridades da televisão, por ter maior impacto sobre os telespectadores e aproximar-se da realidade do mesmo. Marcas e empresas estão cada vez mais interessadas em encontrar maneiras de alavancar "figuras populares" como embaixadores da marca nas mídias sociais, e esses não são necessariamente cantores famosos, atores ou atletas (SOKOLOVA; KEFI, 2019). Por isso, muitos atores, modelos, esportistas, músicos e até chefs de cozinha começaram a se introduzir nas redes sociais para exercitar seu poder de influência e garantir a permanência no mercado publicitário.

Conforme relatado recentemente por um estudo conduzido pela Business Insider (GALLAGHER, 2018), é crítico para muitas marcas encontrar e gerenciar relacionamentos com influenciadores de mídias sociais. Segundo o mesmo estudo, os investimentos nessa área devem alcançar entre US $\$ 5$ bilhões e US $\$ 10$ bilhões em 2022, especialmente nos setores de moda, beleza, educação e turismo. Considerando que muitos outros estudos estão relatando resultados (STATISTA, 2018), a área de pesquisa conhecida como "marketing de influenciadores" ainda é limitada (DE VEIRMAN et al., 2017; ARAL, 2011), e a pesquisa sobre influenciadores de mídia social ainda é relativamente escassa (GODEY et al. 2016).

Muitas marcas ainda estão aprendendo como fazer para ter uma estratégia especifica para os influenciadores digitais. A cultura off-line das marcas ainda é dominante, apesar de que já começa a ficar clara a diferença entre o que é uma celebridade e o que é um influenciador.

Diante o contexto apresentado, esse artigo tem como objetivo verificar a atuação de influenciadores digitais na intenção de compra dos consumidores e se essa influência é alterada quando o produto é de baixo envolvimento ou alto envolvimento. $\mathrm{O}$ artigo está estruturado em cinco partes: introdução, referencial teórico, com a finalidade de fornecer os fundamentos teóricos para a pesquisa de campo e trazer os principais conceitos, metodologia, análise dos resultados, discussão dos resultados e conclusão.

\section{REFERENCIAL TEÓRICO}

\subsection{Comportamento do Novo Consumidor}

As transformações, tanto econômicas quanto sociais, acompanham os avanços tecnológicos e essas mudanças proporcionadas são significativas no comportamento dos consumidores, que passam a se adaptar aos meios disponíveis e a diversas plataformas digitais existentes para funções diversas. No entanto, existem vários motivos que levam ao consumo da tecnologia e podem ser desde a busca por informações, otimizar a comunicação, a compra "online", trabalho até diversão, como revela Lopes et al. (2014), que menciona a criação de um conjunto de entretenimento.

As gerações são instruídas a seguir o comportamento predominantemente de sua época, normalmente destoando das características desenvolvidas pelas gerações passadas. Nesse sentido, a internet, como ferramenta de comunicação, é amplamente utilizada e divulgada entre os consumidores atuais, tornando-se uma forma rápida e segura para transações do comércio tecnológico, fomentando o surgimento de métodos de marketing digital e, com ele, a necessidade de análise do usuário consumidor deste meio. É consenso que a internet possibilitou diminuir distâncias físicas, economizar o tempo e ampliou os canais de compras, por isso é possível afirmar que os meios virtuais facilitam a vida do consumidor e fornecem informações para embasar as decisões durante o processo de escolha.

Segundo Benkler (2006, p. 126), o novo consumidor é classificado como aquele usuário mais ativo e produtivo que os consumidores da economia industrial da informação. Em vista disso, Almeida e Ramos (2012) afirmam que o consumidor está à procura daquilo que deseja. Este fator inclui os processos 
decisórios que antecedem essas ações e as sucedem, afirmando que as características permanentes dos indivíduos e as variáveis sociológicas influenciam neste comportamento e, consequentemente, no processo de decisão de compra. Para Blackwell, Miniard e Engel (2009), os consumidores normalmente passam por sete estágios maiores de tomada de decisão, conforme demonstrado na Figura 1. A partir da compreensão dos profissionais de marketing em relação a estes estágios de tomada de decisões dos consumidores, podem descobrir porque as pessoas compram produtos ou deixam de comprar determinadas mercadorias e que tipo de estratégia utilizar para que comprem mais.

FIGURA 1 - Tomada de Decisão do Consumidor

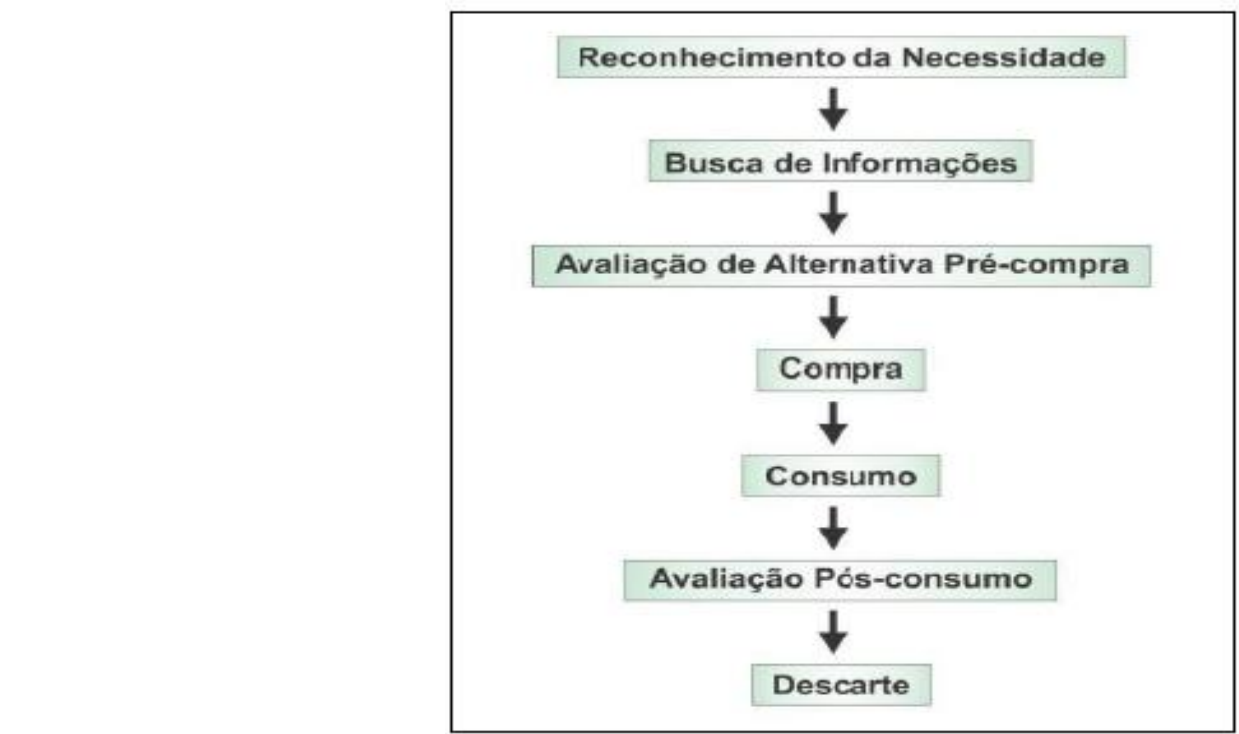

FONTE: Blackwell, Miniard e Engel (2009, p. 73)

Conforme a interpretação de Lopes e Silva (2011), o modelo proposto na Figura 1 sugere que o comportamento de compra tem como antecedentes a pesquisa e as informações sobre o produto. Para isso, as informações existentes sobre os atributos dos produtos e as informações prévias que este consumidor possui se fundem,gerando a atitude de compra que pode ser relacionada com a investigação e avaliação das expectativas, resultando na motivação para a realização ou não da aquisição. $O$ consumidor deste contexto é influenciado por diversas fontes, dentre elas, os aspectos culturais, sociais e psicológicos que se somam às vivências de cada pessoa e, assim, se tornam determinantes de seu comportamento, escolhas e desejos.Nesse sentido, as celebridades cumprem papel importante, porque servem como fontes de estímulos para o consumo,por meio das publicidades disponíveis nas mídias sociais.

\subsection{Mídias Sociais}

A época em que vivemos está marcada pelo uso da mídia social como um instrumento efetivo para divulgação, exposição e expressão pessoal. Terra (2011) define mídia social como aquela utilizada pelas pessoas através de tecnologias e políticas na web, com a finalidade de compartilhar ideias, opiniões, experiências e perspectivas. Com pensamento semelhante, Palagi (apud Sousa e Gollner, 2014, p. 4) afirma que as mídias sociais "são ferramentas online projetadas para permitir a interação social a partir do compartilhamento e da criação colaborativa de informação nos mais diversos formatos".

Sousa e Gollner (2014) destacam a diferença entre mídias sociais e redes sociais. Eles explicam que o Facebook e o Twitter, por exemplo, são mídias sociais com perfis de rede social online, pois têm como objetivo principal o contato e a interação entre os membros que as utilizam. Essas são plataformas digitais, ou seja, antes de serem ferramentas de relacionamento online, são mídias sociais.

Telles (2010) também destaca que várias pessoas utilizam os termos mídias sociais e redes sociais como termos indistintos, porém rede social é uma categoria das mídias sociais. As redes sociais são ambientes que têm como objetivo reunir pessoas que, ao serem inscritos, podem expor seu perfil com dados (fotos pessoais, textos, mensagens e vídeos) e interagir com outras pessoas. Sendo assim, Facebook e Myspace, por exemplo, são redes sociais. Já, por exemplo, Twitter (microblogging), YouTube (compartilhamento de vídeos), Slide Share (compartilhamento de apresentações), Digg (agregador), Flickr (compartilhamento de fotos) e mais as redes sociais são o que compõem as mídias sociais.

Os dois grandes objetivos da mídia social são fornecer o compartilhamento de conteúdo e poder realizar diálogos e conversações. As redes estruturadas de usuários no ciberespaço são formadas através 
de interesses afins e similaridades temáticas, em que pautam, incentivam e estimulam a ação coletiva de seus membros através de ferramentas como Blogs, Twitter, Facebook, MySpace, Instagram, entre outros que emergem constantemente (TERRA, 2011).

\subsection{Mídias Sociais e Divulgação de Marca}

Coutinho (2007) destaca que as empresas descobriram a eficácia das mídias sociais para divulgação de marca e a estão utilizando para estreitar o relacionamento com o consumidor final. Bellato e Lima (2010) afirmam que, mais do que simplesmente um nome, um logotipo, uma embalagem e design, as marcas seriam produto de uma experiência total do consumidor ou, até mesmo, de todos os públicos estratégicos da organização. Além disso, a marca possui o poder de impactar a maneira pela qual as pessoas veem os produtos, pois, geralmente, os consumidores não veem apenas os produtos e serviços de forma absoluta, mas associam-nos às marcas, que podem servir para alavancá-los ou prejudicá-los.

Mitchell e Olson (1981) definem atitude como sendo a avaliação interna que um indivíduo realiza acerca de um objeto, ou seja, a atitude envolve ligação forte entre percepção e imaginação de cada indivíduo. Fishbein e Ajzen (apud Brakus, Schimitt e Zarantonello, 2009, p. 53) referem-se à atitude em relação a uma marca como sendo "as avaliações gerais que surgem com base em crenças ou reações afetivas automáticas".

Segundo Zarantonello e Schmitt (2010), a atitude perante a marca é uma avaliação unidimensional da marca que, previsivelmente, estimula um comportamento. Atitude perante a marca é a predisposição para responder, positiva ou negativamente, a uma determinada marca, após o indivíduo ter sido estimulado através da publicidade. (PHELPS; HOY, 1996)

Telles (2010) apresenta como o uso do Facebook pode ser explorado para que as empresas possam divulgar suas marcas. $\mathrm{O}$ autor afirma que, ao criar um perfil, a empresa mostra sua presença na rede e é a página mais procurada em pesquisas online. Além disso, pode utilizar o Facebook para promoção de eventos em que leva notícias da empresa para o público. O envio de mensagens funciona muito bem para conseguir contato com o público de interesse. É possível realizar pesquisa de mercado com seu público-alvo através do Facebook, pode participar de grupos pertinentes, válido para entrar em contato com o público, pode criar um grupo para seu negócio (criação de uma comunidade em torno da marca da empresa), entre outros benefícios.

Além dos benefícios que as redes sociais fornecem às empresas citadas anteriormente, Sousa e Gollner (2014) mencionam que podem emergir comentários negativos que podem denegrir a imagem de uma empresa em curto espaço de tempo. Esse fato se deve à característica das plataformas interativas que é a sua rápida multiplicação. Uma mensagem, verdade ou não, pode atingir milhares de pessoas em um curto intervalo de tempo. A conquista e manutenção de um bom convívio nas redes sociais da internet se fundamentam na valorização da interação com os internautas, gerando um respeito mútuo entre organização e seus seguidores.

\subsection{Relação entre Influenciadores e Marcas}

Ao passo que o modelo de marketing atual de massa está evoluindo para um modelo mais pessoal e direcionado para um determinado público alvo, percebe-se que as empresas se adéquam a estas mudanças e passam a alinhar suas estratégias para alcançar o público-alvo. $\mathrm{Na}$ internet, o consumidor detém o controle e a liberdade de expor sua opinião sobre uma marca ou produto, embora esta marca não seja ativa na web, sofre influência dos comentários dos consumidores com seus relatos (KOTLER, 2012). Os blogs passaram de diários pessoais para veículos de comunicação por causa do aumento da audiência e credibilidade com o público que se identifica com o influenciador digital, e esses, por sua vez, passam a ser produtores de conteúdo na mídia, utilizando-se dos meios para a veiculação de mensagens publicitárias. As marcas se aproximam do público-alvo através dos influenciadores digitais. Uma das formas utilizadas é posts pagos, com objetivo de divulgar, anunciar ou vender determinado produto. Para isso, ocorre uma seleção do perfil do influenciador desejado e grau de alinhamento com os valores da marca, além da análise do número de seguidores que ele possui e se esse público condiz com possíveis usuários, para só, então, tomar a decisão final.

O grau de credibilidade das pessoas em outros usuários da rede é superior ao da instituição, pois os consumidores cada vez enxergam a mídia social como uma fonte confiável de informação para compartilhar opiniões. Em um mundo que está saturado por propagandas, muitas pessoas se tornaram mais céticas em relação à publicidade. Nas mídias sociais, podemos identificar quem são os líderes de opinião em um assunto específico e, por meio do trabalho de relações públicas, desenvolver um relacionamento com eles, para que essa liderança possa ser aplicada em benefício da marca. 


\subsection{Endosso de Celebridades e Intenção de compra}

Uma figura importante que faz parte das mídias sociais são as celebridades. Ahmed et al. (2015) definem celebridades como aquelas que são conhecidas por um grande número de pessoas. Eles são singulares e possuem características como atração, padrão de vida incomum ou habilidades especiais que não são comumente encontrados em pessoas comuns. As celebridades geralmente englobam os atores, modelos, artistas e atletas.

Segundo Chan, LeungNg e Luk (2013), as celebridades podem ser conceituadas como um grupo de referência influente e, portanto, um recurso poderoso para as empresas divulgarem sua marca. Elas podem testemunhar sobre os benefícios de usar um produto, endossar um produto ou atuar como porta-voz de uma marca por um longo período. Além disso, os autores afirmam que o endosso de celebridades é uma estratégia comum de comunicação de marketing para construção da imagem de marca.

Roy, Gamooh e Koh (2012, p. 33) definem uma celebridade endossadora como sendo "um indivíduo que aproveita de seu reconhecimento público em nome de um bem de consumo, aparecendo com ele em algum tipo de publicidade".

McCracken (1989) propôs um modelo de como acontece a transferência da marca para o consumidor através do endosso de celebridades. Esse modelo de transferência é composto por três estágios. O primeiro estágio consiste que a credibilidade e a experiência de um endossante transferem significado para sua imagem pública. Após isso, o endossante transmite significado para a marca que está sendo endossada e, por fim, há a transferência do significado para os consumidores. Ou seja, segundo o autor, o modelo de transferência de significado está relacionado às características culturais residentes em uma celebridade, as quais vão além da pessoa e são transmitidas aos produtos.

Através do estudo de Ohanian (1990), o autor verificou que a credibilidade do endossante envolve três dimensões: atratividade, expertise e confiabilidade. Goldsmith, Lafferty e Newell (2000) verificaram que a credibilidade dos endossantes pode influenciar atitudes do consumidor em relação à propaganda, à marca e à intenção de compra. A intenção de compra é definida por Phelps e Hoy (1996) como a probabilidade de um indivíduo comprar um determinado produto, enquanto Belch e Belch (2004) acrescentaram comprar uma determinada marca ou produto.

Nas experiências de compra de bens, Mowen e Minor (2003) utilizam os termos produtos com alto envolvimento e baixo envolvimento. Um produto de alto envolvimento é aquele em que o consumidor avalia com base nos atributos e no grau de envolvimento afetivo com o produto. Em outras palavras, não é um produto comprado sempre, tem alto custo, é avaliado pelo grupo de referência, aí, então, o consumidor entra em um processo mais complexo de compra que envolve pesquisa, comparação, avaliação, tempo e outros recursos. Já um produto de baixo envolvimento é aquele em que o consumidor usa uma avaliação mais simples, baseada em crenças rudimentares sobre as opções disponíveis com pouco envolvimento emocional. Ou seja, um produto é considerado de baixo envolvimento quando não é avaliado pelo grupo de referência, é de uso privado, de conveniência, e comprado com alta frequência. Diante disso, o consumidor certamente adotará um processo de compra rotineira: sua decisão é automática, sem grandes rodeios.

\section{METODOLOGIA}

A pesquisa buscou verificar se há diferença significativa na relação que as pessoas associadas têm sobre um produto de alto envolvimento e um produto de baixo envolvimento quando estes são apresentados por uma celebridade ou não e se essa apresentação da marca pela celebridade interfere na intenção de compra desses produtos. Para isso, foi realizada uma pesquisa quantitativa descritiva explicativa, através de um experimento por meio de questionário digital. Nesse sentido, a amostra foi não probabilística por conveniência, já que a divulgação ocorreu na página do "Facebook" das autoras e a análise dos dados foi realizada através de métodos estatísticos descritivos simples.

Conforme Acevedo e Nohara (2009), a pesquisa descritiva pode ser utilizada quando o objetivo do estudo for descrever as características de um grupo, estimar a proporção dos elementos de determinada população e descobrir ou compreender as relações entre os elementos envolvidos no fenômeno em questão. De acordo com Prodanov e Freitas (2009), para a coleta de dados, são utilizadas técnicas específicas como a entrevista, o formulário, o questionário, o teste e a observação, sendo que, na presente pesquisa, será utilizada a aplicação de questionários eletrônicos.

Segundo Gil (2010), as pesquisas explicativas buscam explicar por que determinados fenômenos ocorrem e quais fatores causam e contribuem para sua ocorrência. Gil (2010) complementa que estas pesquisas são as que mais aprofundam o conhecimento da realidade, pois têm finalidade de explicar a razão, o porquê das coisas. Esta pesquisa também tem cunho explicativo, pois verificará se a notoriedade dos indivíduos utilizados em propagandas impacta na intenção de compras de produtos com alto envolvimento e baixo envolvimento dos consumidores.

Para Marconi e Lakatos (2010, p. 50), "os levantamentos caracterizam-se pela coleta das informações entre um grande número de pessoas e pela análise quantitativa de dados". No entanto, as 
técnicas utilizadas para o levantamento mostram-se bastante úteis para obter informações acerca do que a pessoa "sabe, crê ou espera, sente ou deseja, pretende fazer, faz ou fez, bem como a respeito de suas explicações ou razões para quaisquer das coisas precedentes" (GIL, 2010, p. 103).

O levantamento dos dados foi efetuado por autopreenchimento pela internet em questionário cadastrado e disponibilizado pelo aplicativo Google Docs, contendo as instruções para seu preenchimento e precedido de informações sobre os objetivos da pesquisa e o uso de seus resultados exclusivamente para fins acadêmicos. A pesquisa obteve 120 participantes que foram convidados a participar voluntariamente e a coleta dos dados ocorreu entre os dias 15/09/2017 e 05/10/2017. O instrumento de coleta dos dados foi organizado contendo 84 perguntas; sendo que 80 perguntas foram avaliadas pelos entrevistados através de uma escala do tipo Likert, em que expressaram o seu grau de concordância ou discordância frente aos aspectos solicitados. O restante das questões dividiu-se em uma pergunta do tipo descritiva e três questões objetivas para caracterização da amostra.

Para mensuração da Credibilidade do Endossante, foi utilizada a escala desenvolvida por Ohanian (1990), que envolve as três dimensões (confiabilidade, expertise e atratividade). Para a mensuração da Intenção de Compra, adotou-se a escala desenvolvida por Bruner e Hensel (1998) e para ambas foram utilizadas escala tipo Likert.

Para definir os estímulos dos experimentos, foi realizada uma pesquisa em site de busca sobre quais são as celebridades brasileiras mais seguidas nas redes sociais. Dentre o rol de artistas apresentados, foi escolhido o apresentador Luciano Huck e a cantora Ivete Sangalo para compor os cenários da pesquisa. A escolha dos produtos foi baseada em Popadiuk (1993), pois, segundo o autor: "os produtos de alto envolvimento compreendem imóveis, carros ou equipamentos eletroeletrônicos" (POPADIUK, 1993, p. 84). Já as compras de "produtos disponíveis em supermercados, compreendem os produtos de baixo envolvimento" (POPADIUK, 1993, p. 84). Diante desse contexto, justifica-se a escolha pelo notebook como produto para compor os cenários, cujo foco são produtos de alto envolvimento; já o sabonete foi escolhido para compor os cenários em que o centro são produtos de baixo envolvimento.

O primeiro cenário apresentado aos participantes foi composto pelo produto sabonete com a figura da celebridade Ivete Sangalo, enquanto o segundo cenário foi composto pelo mesmo produto, porém com a figura de uma modelo desconhecida. Para o terceiro cenário, apresentou-se o produto notebook com a celebridade Luciano Huck e, por último, o mesmo produto com a figura de um modelo desconhecido.

Os participantes da pesquisa responderam aos quatro cenários propostos (within-subjects). Goodwin e Goodwin (2013) afirmam que a participação em uma condição pode afetar o comportamento na próxima condição. Nesse estudo, os cenários não foram randomizados conforme sugere a literatura, portanto esta pode ser considerada uma limitação da coleta de dados. Os cenários apresentados no instrumento de coleta de dados são mostrados na figura 2.

FIGURA 2 - Imagens dos estímulos utilizados no questionário

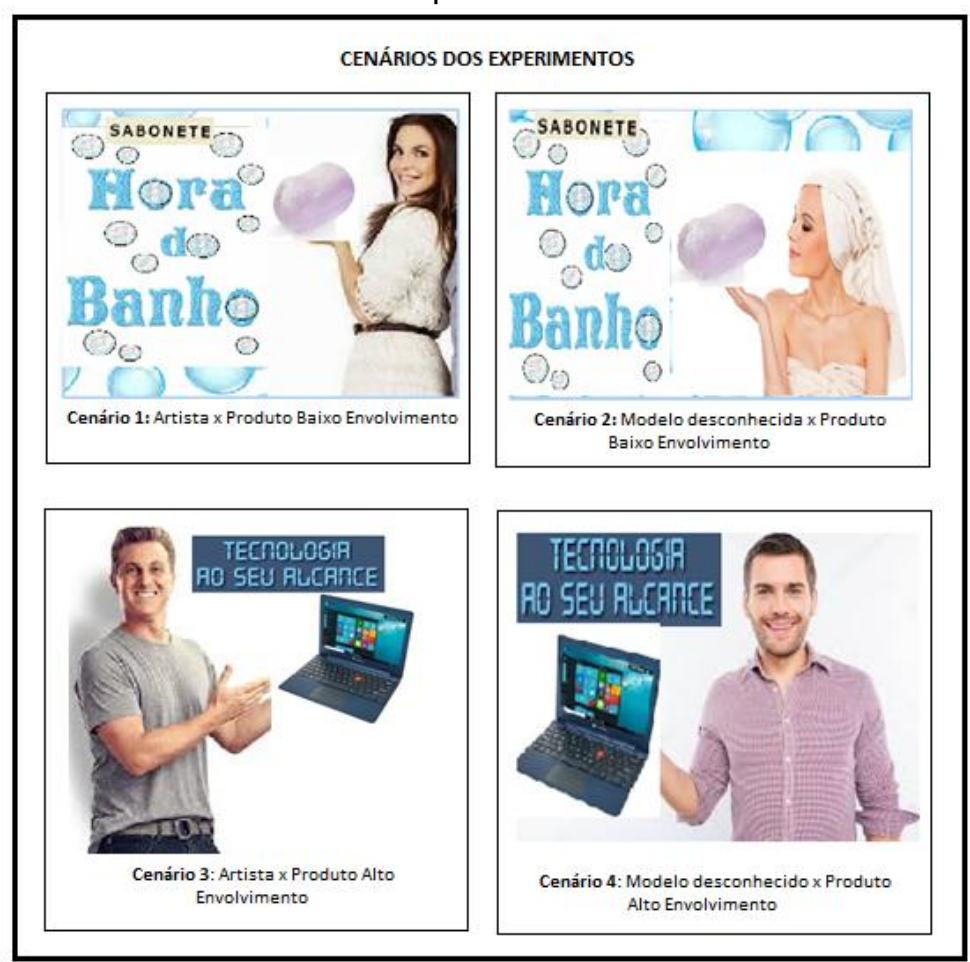

FONTE: Autoras 


\section{ANÁLISE DOS RESULTADOS}

Neste capítulo, serão apresentadas as informações obtidas mediante a análise dos dados gerados através da pesquisa. Por meio desta, foi possível traçar o perfil da amostra estudada e realizar comparações entre as médias alcançadas nas escalas.

\subsection{Caracterização da Amostra}

A amostra foi composta por 120 (cento e vinte) pessoas, sendo a maioria (60 pessoas) com idade compreendida entre 24 e 30 anos. Além disso, a idade mínima e máxima foi de 18 e 61 anos, respectivamente. Ademais, a participação do sexo feminino como respondente foi efetivamente maior com $71,7 \%$, enquanto a participação masculina contou com $28,3 \%$ do total de respondentes, conforme demonstrado no gráfico 1.

GRÁFICO 1 - Gênero dos participantes
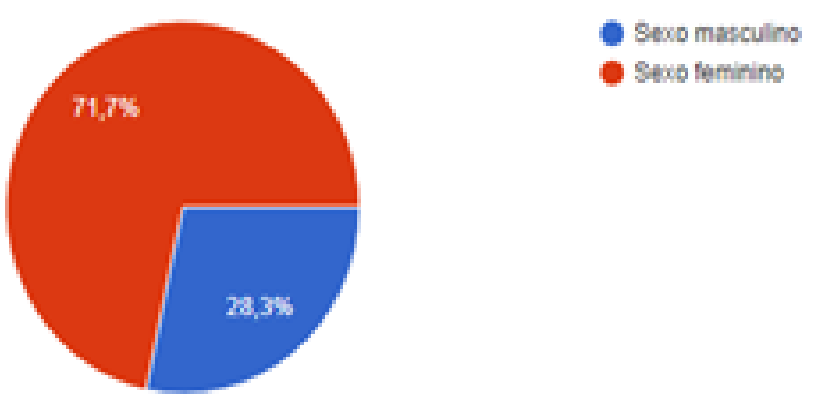

FONTE: Autoras

Em relação à escolaridade da amostra obtida, pode-se concluir que condiz com o esperado, visto que o questionário eletrônico foi disponibilizado no Facebook das autoras e os indivíduos de suas redes de relacionamento são, em sua grande maioria, compatíveis com a escolaridade das mesmas. Então, a maioria da amostra tem ensino superior completo, representando $37,5 \%$ do total de respondentes e, logo após, com grande representatividade vêm os pós-graduados com $34,2 \%$ do total. Nesse caso específico, a baixa representatividade das pessoas com o ensino médio completo para baixo pode ter influência do círculo de amizades das autoras, mas também pode se dar pelo fato de que o modo escolhido para divulgação tende a despertar mais o interesse para participação das pessoas que estão ou estiveram no meio acadêmico, já que estas compreendem a importância do preenchimento do formulário para o fomento à pesquisa. $O$ detalhamento da escolaridade dos respondentes encontra-se ilustrado no gráfico 2 .

GRÁFICO 2 - Escolaridade dos participantes

\section{FONTE: Autoras}

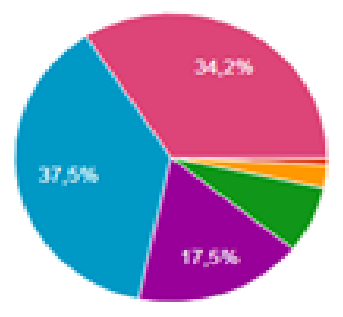

- Ensino Fundamental incompleto

Ensino Fundamental Compieto

Ensino médo incomoleto

- Ensino Medo Completo

- Ensino Superier incompleto

Ensino Superior Completo

- P6s-praduado(a)

Em relação à renda mensal dos respondentes, a maioria (30\%) está compreendida entre 3 e 5 salários mínimos (entre $R \$ 2.811,00$ e $R \$ 4.685,00$ ), com variação grande entre o restante das opções de escolha, sendo que apenas a parte correspondente a mais de 15 salários mínimos tem participação mínima na amostra. Para melhor visualização dos percentuais de renda mensal, foi construído o gráfico 3. 


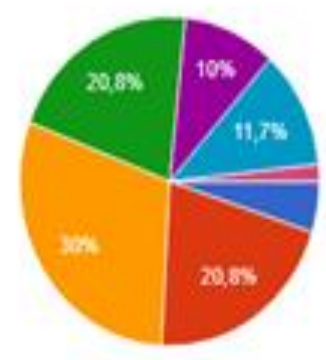

- Ay it selaro minimo (RS 997,00),

- Entre 1 e 3 salarios minimos (entro RS 93700 e RS 281100 \%

- Entre 345 valaries minimos (entre RS 2811,00 e RS 4685.00 )

- Entre 5 e 8 sasaros mirimos jente R5 4 605 e R5 7.496 .00

- Entre 8 e 10 salinos minimos (ontr

- Entre 10 e 15 salinos ninimos iest

- Mas de 15 salános minimos inas

FONTE: Autoras

Dessa maneira, a caracterização da amostra se dá, em sua maioria, composta por jovens entre 24 e 30 anos, com curso superior completo ou mais, e faixa de renda mensal compreendida entre 3 e 5 salários mínimos. Diante disso, por meio da caracterização, pode-se levar a uma melhor compreensão do ponto de vista dos respondentes e, também, evitar generalizações dos resultados descritos nesse artigo. Mesmo referindo-se a um número razoável de respondentes suficientes para validar e dar viabilidade ao estudo, ao mesmo tempo, revela que possuem características bem definidas e próprias.

\subsection{Análise das Médias das Escalas}

Analisando as médias expostas na tabela 1, em relação aos constructos das escalas, têm-se que,em relação à atratividade, a média da celebridade é maior do que a anônima no produto de baixo envolvimento. Já no produto de alto envolvimento, a celebridade tem média significativamente menor do que o anônimo. No constructo expertise em relação ao produto de baixo envolvimento, a anônima tem média maior do que a celebridade; já no produto de alto envolvimento, o anônimo e a celebridade tiveram médias iguais. No tocante à confiabilidade para o produto de menor envolvimento, a celebridade obteve média maior do que a anônima; e no produto de alto envolvimento, a celebridade obteve média menor do que o modelo anônimo. No que se refere à intenção de compra, tanto no produto de baixo quanto no de alto envolvimento, os modelos anônimos alcançaram maiores médias do que as celebridades.

TABELA 1 - Média das escalas

\begin{tabular}{|c|c|c|c|c|c|c|c|c|c|c|c|c|}
\hline \multirow[t]{2}{*}{ Itens da Escala } & \multicolumn{3}{|c|}{$\begin{array}{l}\text { Cenário 1: } \\
\text { Artista X PBE }\end{array}$} & \multicolumn{3}{|c|}{$\begin{array}{l}\text { Cenărio 2: } \\
\text { Desconhecida } \times \text { PBE }\end{array}$} & \multicolumn{3}{|c|}{$\begin{array}{c}\text { Cenărio 3: } \\
\text { Artista X PAE }\end{array}$} & \multicolumn{3}{|c|}{$\begin{array}{l}\text { Cenário 4: } \\
\text { Desconhecido } \mathrm{x} \text { PAE }\end{array}$} \\
\hline & $\mathbf{N}$ & Média & DP & $\mathrm{N}$ & Média & DP & $\mathbf{N}$ & Média & DP & $\mathbf{N}$ & Média & DP \\
\hline $\begin{array}{l}\text { Atratividade } \\
\text { Considero } a(0) \text { modelo... }\end{array}$ & \multicolumn{3}{|c|}{ Média $=3,97$} & \multicolumn{3}{|c|}{ Média $=3,50$} & \multicolumn{3}{|c|}{ Média $=2,54$} & \multicolumn{3}{|c|}{ Média $=3,36$} \\
\hline Não atraente xAtraente & 120 & 3,9 & 1,22 & 120 & 3,53 & 1,2 & 120 & 2,42 & 1,15 & 120 & $3,3: 4$ & 1,01 \\
\hline Sem classe $\mathrm{x}$ Com classe & 120 & 4,2 & 1,04 & 120 & 3,63 & 1,07 & 120 & 3,36 & 1,14 & 120 & 3,52 & 1,05 \\
\hline Feia(o) $\times$ Bonita(o) & 120 & 4,4 & 1 & 120 & 3,96 & 0,98 & 120 & 2,19 & 1,06 & 120 & 3,54 & 1,13 \\
\hline Simples x Elegante & 120 & $3,9.8$ & 1,21 & 120 & 3 & 1,38 & 120 & 2,82 & 1,05 & 120 & 3,31 & 1,19 \\
\hline Nada sexy x Sexy & 120 & 3,4 & 1,31 & 120 & 3,41 & 1,07 & 120 & 1,91 & 1,35 & 120 & 3,13 & 1,06 \\
\hline $\begin{array}{l}\text { Expertise } \\
\text { Para esta campanha } g(0) \text { madela é. }\end{array}$ & \multicolumn{3}{|c|}{ Média $=3,54$} & \multicolumn{3}{|c|}{ Média $=3,70$} & \multicolumn{3}{|c|}{ Média $=3,39$} & \multicolumn{3}{|c|}{ Média $=3,39$} \\
\hline Nada "especialista" $x$ "Especialista" & 120 & 3,04 & 1,29 & 120 & 3,69 & 1,11 & 120 & 3,16 & 1,3 & 120 & 3,36 & 1,03 \\
\hline Inexperiente $x$ Experiente & 120 & 3,42 & 1,25 & 120 & 3,65 & 1,12 & 120 & 3,38 & 1,18 & 120 & 3,38 & 0,99 \\
\hline Desajeitada(o) x Talentosa(o) & 120 & 3,84 & 1,12 & 120 & 3,6 & 1,02 & 120 & 3,56 & 1,28 & 120 & 3,39 & 0,95 \\
\hline Nada gualjficada(o) x Qualificada(o) & 120 & 3,64 & 1,17 & 120 & 3,78 & 1,06 & 120 & 3,31 & 1,2 & 120 & 3,44 & 0,99 \\
\hline Inábil x Hábil & 120 & 3,77 & 1,11 & 120 & 3,8 & 1,07 & 120 & 3,55 & 1,18 & 120 & 3,41 & 1,01 \\
\hline $\begin{array}{l}\text { Confiabilidade } \\
\text { Para esta campanha } a(0) \text { madelo me parece. }\end{array}$ & \multicolumn{3}{|c|}{ Média $=3,93$} & \multicolumn{3}{|c|}{ Média $=3,88$} & \multicolumn{3}{|c|}{ Média = 3,36 } & \multicolumn{3}{|c|}{ Média = 3,46 } \\
\hline Insegura $(0) \times$ Segura $(0)$ & 120 & 4,2 & 1,03 & 120 & 4,06 & 1,09 & 120 & 3,83 & 1,15 & 120 & 3,55 & 0,85 \\
\hline Desonesta (o) x Honesta(o) & 120 & 3,94 & 0,96 & 120 & 3,90 & 1 & 120 & 3,30 & 1,26 & 120 & 3,49 & 0,87 \\
\hline Duvidosa $(0) \times$ Confiável & 120 & 3,84 & 1,04 & 120 & 3,81 & 1,02 & 120 & 3,23 & 1,18 & 120 & 3,4 & 0,85 \\
\hline Mentirosa $(0) \times$ Sincera $(0)$ & 120 & 3,85 & 0,95 & 120 & 3,83 & 2,01 & 120 & 3,24 & 1,2 & 120 & 3,5 & 0,85 \\
\hline Não djgna(o) de confiança x Digna(o) de Confiança & 120 & 3,86 & 1,01 & 120 & 3,81 & 1,18 & 120 & 3,23 & 1,15 & 120 & 3,4 & 0,99 \\
\hline Intenção de Compra & \multicolumn{3}{|c|}{ Média $=3,29$} & \multicolumn{3}{|c|}{ Média $=3,56$} & \multicolumn{3}{|c|}{ Média $=3,14$} & \multicolumn{3}{|c|}{ Mécdia $=3,53$} \\
\hline Improvável x Provåvel & 120 & 3,11 & 1,22 & 120 & 3,55 & 1,17 & 120 & 3,11 & 1,15 & 120 & 3,25 & 1,00 \\
\hline Inexistente $x$ Existente & 120 & 3,37 & 1,13 & 120 & 3,61 & 1,19 & 120 & 3,13 & 1,12 & 120 & 3,37 & 1,00 \\
\hline Não plausível x Plausível & 120 & 3,34 & 1,21 & 120 & 3,59 & 1,13 & 120 & 3,20 & 1,09 & 120 & 3,40 & 1,01 \\
\hline Impossivel x Possivel & 120 & 3,54 & 1,06 & 120 & 3,7 & 1,12 & 120 & 3,27 & 1,12 & 120 & 3,43 & 0,97 \\
\hline Incerta $\times$ Certa & 120 & 3,11 & 1,13 & 120 & 3,35 & 1,35 & 120 & 3 & 1,19 & 120 & 4,20 & 0,96 \\
\hline
\end{tabular}

FONTE: Autoras

${ }^{*}$ PBE: Produto Baixo Envolvimento

${ }^{* *}$ PAE: Produtos Alto Envolvimento 


\section{DISCUSSÃO DOS RESULTADOS}

No produto de baixo envolvimento (sabonete), a celebridade despertou maior atratividade do que no produto de alto envolvimento (notebook). Analisando a expertise dos modelos, a celebridade de baixo envolvimento teve menos aceitação do que a modelo anônima, enquanto, no produto de alto envolvimento, não teve diferença o modelo ser anônimo ou celebridade. Quando a questão em debate é confiabilidade, a celebridade obteve melhores resultados do que a modelo anônima no produto de baixo envolvimento. Mas, quando se trata de produto de alto envolvimento, o modelo anônimo foi classificado pelos respondentes como mais confiável.

A credibilidade do influenciador digital com produto de baixo envolvimento foi o que obteve a maior média $(3,81)$, seguido pela propaganda de pessoa anônima com produto de baixo envolvimento $(3,69)$. Além disso, os dados mostram que a credibilidade do anônimo com o produto de alto envolvimento obteve média maior $(3,40)$ do que a credibilidade do artista com o produto de alto envolvimento $(3,09)$. No que diz respeito à intenção de compra, os respondentes avaliaram como mais possível e certa a possibilidade de comprar os produtos de alto e baixo envolvimento dos modelos anônimos do que das celebridades.

\section{CONCLUSÃO}

A pesquisa buscou verificar se a notoriedade dos indivíduos utilizados em propagandas impacta na intenção de compras de produtos com alto envolvimento e baixo envolvimento. Quanto a esse objetivo, surpreendentemente, chegou-se à conclusão que a associação da marca à celebridade não teve boa aceitação por parte dos consumidores respondentes que avaliaram melhor a possibilidade de compra dos produtos com modelos desconhecidos. A rejeição das celebridades pode ser entendida como possibilidade de ludibriar o consumidor, principalmente os com maior escolaridade, como é o caso da amostra em questão.

Portanto, a afirmação de que a cooptação de influenciadores digitais para propaganda das marcas é uma estratégia eficiente pode ser questionada e apontada como falsa, de acordo com os resultados desta pesquisa. Ainda, levando em consideração os dados coletados e após a análise da relação entre o uso de influenciadores e a intenção de compra de um produto, identificou-se que há relação entre os influenciadores e a intenção de compra, mas ela é negativa. Com isso, identificou-se que não existe relação entre o aumento do consumo e a associação dos produtos com alguma personalidade na internet. Os produtos de baixo envolvimento têm melhor aceitação quanto à associação das celebridades, mesmo não interferindo na intenção de compra. Dessa maneira, foi verificado que o tipo de produto (alto ou baixo envolvimento) apresentado por influenciadores digitais não interfere na intenção de compra do novo consumidor.

Nesse sentido, em contraposição ao senso comum, pode-se perceber que quanto maior a credibilidade da celebridade, maior a influência do endosso na intenção de compra de um produto com alto ou baixo envolvimento. E, ainda, considerando a análise realizada através dos resultados obtidos na comparação das médias, a atratividade e a expertise da celebridade não têm influência no endosso na intenção de compra de um produto com alto envolvimento e não influencia no produto de baixo envolvimento. Além disso, percebe-se que a confiabilidade nas celebridades é sem expressão e produz efeito contrário quanto à influência do endosso na intenção de compra de um produto com alto e baixo envolvimento. Com isso, os respondentes avaliaram como mais atrativo o produto de baixo envolvimento anunciado pela celebridade. O de alto envolvimento teve melhor aceitação anunciada pelo modelo anônimo; a expertise foi melhor avaliada quando não associada a uma celebridade nos produtos de baixo envolvimento, pois, no de alto, não teve variação, confiabilidade, cuja intenção de compra é maior quando não envolve celebridades.

Dessa forma, há contribuições importantes nos resultados deste estudo para o marketing digital e para a publicidade envolvendo influenciadores digitais. Buscou-se entender o comportamento do consumidor para produtos associados às celebridades, tanto nos que demandam maior envolvimento quanto nos classificados como de menor envolvimento. O estudo mostrou a necessidade dos gerentes de marketing em realizar estudos e pesquisas para verificar se realmente a contratação de influenciadores digitais é essencial para a campanha, pois, muitas vezes, atores desconhecidos podem desempenhar a mesma função, porém com um custo muito menor. Além disso, destaca-se a importância na busca pelo influenciador que esteja mais alinhado com os valores da marca, justamente para passar a sensação de verdade na sua fala e ter o resultado esperado, seja na disseminação de uma informação, seja para aumentar porcentagem de vendas.

Como limitações do estudo, pode-se destacar a amostra, pois possui características bem definidas, que apontam as opiniões de pessoas na fase adulta, que possuem alta escolaridade e renda considerável em comparação com a população brasileira. Além disso, os influenciadores digitais utilizados no estudo podem ter se envolvido em polêmicas, o que pode ter despertado, nos participantes, uma sensação negativa e de repúdio por grande parte dos respondentes. 
Uma das sugestões para pesquisas futuras é a aplicação do mesmo estudo para outras amostras mais abrangentes ou com características opostas para posterior comparação e confronto de resultados para verificar se há uma idade que os consumidores são mais suscetíveis à influência de celebridades ou se a variação de renda interfere na intenção de compra dos produtos anunciados pelas celebridades.

\section{REFERÊNCIAS}

ACEVEDO, C.; NOHARA, J. Monografia no curso de Administração: guia completo de conteúdo e forma. 3. ed. São Paulo: Atlas, 2009.

AHMED, R.R., SEEDANI, S.K., AHUJA, M.K.; PARYANI, S.K. (2015). Impact of Celebrity Endorsement on Consumer Buying Behavior.Journal of Marketing and Consumer Research. Vol. 16, p. 12-20.

ALMEIDA, V.; RAMOS, M. Os Impactos das reclamações On-line da lealdade dos Consumidores: Um estudo Experimental. Revista RAC - Revista de Administração Contemporânea, Rio de Janeiro, v. 16, n. 5, p. 664-683, set./out., 2012.

ARAL, S. Commentary-identifying social influence: A comment on opinion leadership and social contagion in new product diffusion. Marketing Science, v. 30, n. 2, p. 217-223, 2011.

BARGER, V.; PELTIER, J. W.; SCHULTZ, D. E. Social media and consumer engagement: a review and research agenda. Journal of Research in Interactive Marketing, v. 10, n. 4, p. 268-287, 2016.

BATRA, R.; AHTOLA, O. Measuring the hedonic and utilitarian sources of consumer attitudes. Marketing Letters, v. 2, n. 2, p. 159-170, 1991.

BELCH, G.; BELCH, M. Advertising and Promotion: an Integrated Marketing Communications Perspective. 6. ed. New York: The McGraw-Hill Companies, 2004.

BELLATO, L; LIMA, M. Desafios e Oportunidades para as Marcas no Contexto da Era Digital: estudo de caso da campanha de Barack Obama. PMKT - Revista Brasileira de Pesquisas de Marketing, Opinião e Mídia. São Paulo. Vol. 3, n. 1, p. 8-16, 2010.

BENKLER, Y. The Wealth of Networks: How Social Production Transforms Markets and Freedom. New Haven, Conn: Yale University Press, 2006.

BLACKWELL, R.; MINIARD, P.; ENGEL, J. Comportamento do Consumidor. Tradução da $9^{a}$ edição norte-americana. São Paulo: Cengage Learning, 2009.

BOOTH, N.; MATIC, J. Mapping and leveraging influencers in social media to shape corporate brand perceptions. Corporate Communications: An International Journal, v. 16, n. 3, p. 184-191, 2011.

BRAKUS, J.; SCHIMITT, B.; ZARANTONELLO, L. Brand Experience: What is it? How do we measure it? And does it affect loyalty? Journal of Marketing, Vol. 73, n. 3, p.p. 52-68, 2009.

BRUNER, G.; HENSEL, P. Marketing scales handbook: a compilation of multi-items measures. v. 2, Chicago: American Marketing Association, 1998.

CHAN, K., LEUNG NG, Y.; LUK, E. Impact of celebrity endorsement in advertising on brand image among Chinese adolescents. Young Consumers, Vol. 14, n. 2, pp.167-179, 2013.

COUTINHO, M. Marketing e comunidades digitais: do discurso ao diálogo. Revista da ESPM, p. 28-39, 2007.

DE VEIRMAN, M.; CAUBERGHE, V.; HUDDERS, L. Marketing through Instagram influencers: the impact of number of followers and product divergence on brand attitude. International Journal of Advertising, v. 36, n. 5, p. 798-828, 2017.

GIL, A. Como Elaborar Projetos de Pesquisa. 5. ed. São Paulo: Atlas S.A., 2010.

GODEY, B.; MANTHIOU, A.; PEDERZOLI, D.; ROKKA, J.; AIELLO, G.; DONVITO, R.; SINGH, R. Social media marketing efforts of luxury brands: Influence on brand equity and consumer behavior. Journal of business research, v. 69 , n. 12, p. 5833-5841, 2016.

GOLDSMITH, R. E.; LAFFERTY, B. A.; NEW ELL, S. J. The impact of corporate credibility and celebrity credibility on consumer reaction to advertisements and brands. Journal of Advertising, v. 29, n.3, p. 43-54, 2000.

GOODWIN, C.; GOODWIN, K. A. Research in psychology methods and design. John Wiley \& Sons, 2016.

HIRSHCHMAN, E. C. Predictors of self-projection: fantasy fulfillment and escapism. Journal of Social Psychology, v. 120, n. 1, p. 63-76, 1983.

HOLBROOK, M. B.; HIRSHCHMAN, E. C. The experiential aspects of consumption: consumer fantasies, feelings, and fun.Journal of Consumer Research, v. 9, p. 132-140, 1982.

KLASSEN, K,; BORLEIS, E.; BRENNAN, L.; REID, M.; MCCAFFREY, T.; LIM, M. What people "like": analysis of social media strategies used by food industry brands, lifestyle brands, and health promotion organizations on Facebook and Instagram. Journal of medical Internet research, v. 20, n. 6, p. e10227, 2018.

KOTLER, P. Marketing 3.0: as forças que estãodefinindo o novo marketing centrado no ser humano. Trad. Ana Beatriz Rodrigues, Rio de Janeiro: Elsevier, 2012.

LIU, B. F.; JIN, Y.; BRIONES, R.; KUCH, B. Managing turbulence in the blogosphere: Evaluating the blog-mediated crisis communication model with the American Red Cross. Journal of Public Relations Research, v. 24, n. 4, p. 353-370, 2012. 
LOPES, A.; GROSSI, M.; SILVA, M.; GALVAO, R. Geração Internet: quem são e para que vieram. Revista CTS, v. 9 , n. 26, p. 39-54, 2014.

LOPES, E.; SILVA, D. Modelos Integrativos do Comportamento do Consumidor: uma Revisão Teórica. REMark Revista Brasileira de Marketing, v. 10, n. 3, p. 03-23, 2011.

MARCONI, M.; LAKATOS, E. Fundamentos de Metodologia Científica. 7. ed. São Paulo: Atlas, 2010.

MARKETHUB, (2016), Influencer marketing vs word-of-mouth marketing. Disponível em: <https://www.markethub.io/influencer-marketing-vs-word-of-mouth-marketing/>

MCCRACKEN, G. Who is the celebrity endorser? Cultural foundations of the endorsement process, Journal of Consumer Research, v. 16, n. 3, p. 310-21, 1989.

MITCHELL, A.; OLSON, J. Are product attribute beliefs the only mediator of advertising effects on brand attitude? Journal of Marketing Research, v. 18, n. 3, p. 318-331, 1981.

MOWEN, J., MINOR, M. Comportamento do consumidor. 1. ed. Tradução Vera Jordan. Ed. São Paulo: Prentice Hall, 2003.

OHANIAN, R. Construction and validation of a scale to measure celebrity endorsers' perceived expertise, trustworthiness, and attractiveness. Journal of Advertising, v. 19, n. 3, p. 39-52, 1990.

PHELPS, J.; HOY, M. The Aad-Ab-PI Relationship in children: the impact of brand familiarity and measurement timing. Psychology \& Marketing, v. 13, n. 1, 77-101, 1996.

POPADIUK, S. O processo de envolvimento na compra de um produto. Revista de Administração da USP, v. 28 , n. $2,1993$. PRODANOV, C.; FREITAS, E. Metodologia do Trabalho Científico. Novo Hamburgo: Feevale, 2009.

RAGGATT, M.; WRIGHT, C.; CARROTTE, E. JENKINSON, R.; MULGREW, K.; PROCHARD, I.; LIM, M. "I aspire to look and feel healthy like the posts convey": engagement with fitness inspiration on social media and perceptions of its influence on health and wellbeing. BMC public health, v. 18, n. 1, p. 1002, 2018.

ROY, S.; GAMOOH, B.; KOH, A. Predicting the effectiveness of celebrity endorsements using the balance theory. Journal of Customer Behaviour. v. 11, n. 1, p. 33-52, 2012.

SCHMITT, B.; ZARANTONELLO, L. Using the brand experience scale to profile consumers and predict consumer behavior. Journal of Brand Management, v. 17, n. 7, p. 532-540, 2010.

SOKOLOVA, K.; KEFI, H. Instagram and YouTube bloggers promote it, why should I buy? How credibility and parasocial interaction influence purchase intentions. Journal of Retailing and Consumer Services, 2019.

SOUSA, B.; GOLLNER, A. As Mídias Sociais como Ferramentas de Comunicação Organizacional: um estudo de caso na Embraer. In: XIX Congresso de Ciências da Comunicação na Região Sudeste, Vila Velha, Anais, 2014.

STATISTA. Statista dossier on influencer marketing in the United States and worldwide.2018.Disponível em: https://www.statista.com/study/28362/influence-marketing-statista-dossier/

TELLES, A. A revolução das mídias sociais: Cases, Conceitos, Dicas e Ferramentas. São Paulo: M Books do Brasil Editora Ltda., 2010.

TERRA, C. O que as organizações precisam fazer para serem bem vistas nas mídias sociais sob a ótica da Comunicação Organizacional e das Relações Públicas. In: V Congresso Brasileiro Científico de Comunicação Organizacional e Relações Públicas da Abrapcorp, São Paulo, Anais, 2011. 
